\title{
Emission and Performance Optimization of Marine Four-Stroke Dual-Fuel Engine Based on Response Surface Methodology
}

\author{
Huaiyu Wang $\left(\mathbb{D}\right.$, Huibing Gan $\left(\mathbb{D}\right.$, Guanjie Wang $\left(\mathbb{D}\right.$, and Guoqiang Zhong $\mathbb{D}^{\mathbb{D}}$ \\ Marine Engineering College, Dalian Maritime University, Dalian 116026, China \\ Correspondence should be addressed to Huibing Gan; ghbzq@dlmu.edu.cn
}

Received 4 September 2019; Accepted 30 December 2019; Published 24 January 2020

Academic Editor: Hua Fan

Copyright (C) 2020 Huaiyu Wang et al. This is an open access article distributed under the Creative Commons Attribution License, which permits unrestricted use, distribution, and reproduction in any medium, provided the original work is properly cited.

As the emissions regulations have become more stringent, reducing $\mathrm{NO}_{X}$ emissions is of great importance to the shipping industry. Due to the price and emissions advantages of natural gas, the diesel-natural gas engines have become an attractive solution for engine manufacturers. Firstly, in this paper, the $\mathrm{NO}_{X}$ emissions prediction model of a large marine four-stroke dualfuel engine is built by using AVL-BOOST. In addition, the model is further calibrated to calculate the performance and emissions of the engine. Then, the influences of boost pressure, compression ratio, and the timing of intake valve closing on engine performance and emissions are analyzed. Finally, the response surface methodology is used to optimize the emissions and performance to obtain the optimal setting parameters of the engine. The results indicate that the response surface method is a highly desirable optimization method, which can save a lot of repeated research. Compared with the results from manufactured data, the power is increased by $0.55 \%$ and the BSFC, the $\mathrm{NO}_{X}$ emissions, and the peak combustion pressure are decreased by $0.60 \%, 13.21 \%$, and $1.51 \%$, respectively, at low load.

\section{Introduction}

In the past few years, the increasing emissions of the marine engine including $\mathrm{CO}_{2}, \mathrm{NO}_{X}$, and $\mathrm{SO}_{X}$ account for $2-3 \%$ of global emissions. In order to reduce the shipbuilding industry's impact on the environment, IMO built a lot of laws and regulations to protect the environment. IMO advocates EEDI (Energy Efficiency Design Index) and EEOI (Energy Efficiency Operation Index) for improving the energy efficiency of ships and reducing greenhouse gas emissions from ships. In addition, DNV GL classification society [1] demonstrates various implementation schemes to meet Tier III requirements such as the EGR (Exhaust Gas Recirculation) [2], SCR (Selective Catalytic Reduction), alternative fuels [3], engine inner reconstruction, cylinder direct injection [4], FEW (fuel water emulsion) [5], and HAM (humid air Motor) [6]. The EGR method can reduce cylinder combustion temperatures and reduce $\mathrm{NO}_{X}$ emissions. The SCR method is efficient but it is expensive. The FEW and HAM methods are difficult in business [7]. As an alternative, fuel natural gas has the superiority of emissions reduction [8]. Besides taking the market fluctuations and fuel prices into account, natural gas has a more attractive price advantage [9]. In order to meet the strict scheme, international engine manufacturers, including MAN and Wartsila, have turned their research focus on reducing gas emissions. The PFI (port fuel injection) method is mainly used in the four-stroke dual engine such as Wartsila DF (dual-fuel) and MAN Diesel \& Turbo DF series engines. This operation mode approaches to the Otto cycle and fewer emissions due to the lower maximum combustion temperature. This method is simple and easy to implement and can be used for the retrofitting of old diesel engines. In another way, both the gas fuel injection and liquid fuel injection are directly injected into a cylinder with different injection timing which is similar to the diesel cycle. In the early research, there were many methods to optimize the engine performance such as the fuel injection timing [10], the Miller cycle [11], and RCCI (reactivity controlled compression ignition) [12]. However, due to the expensive experiment of large marine engines, many optimizations focused on the cylinder part such as the fuel injection, Miller 
cycle [13], and EGR [14] by CFD (Computational Fluid Dynamics) tools. In the previous research work, Mavrelos and Theotokatos [15] built a large marine two-stroke dualfuel engine model to optimize the engine performance via parametric runs. Stoumpos et al. [16] optimized a fourstroke dual fuel engine through a similar method. It is not a better optimization method because it does not have the combined effect of the parameters. The RSM (Response Surface Methodology) method is a collection of mathematical and statistical methods, which can be used to model and analyze problems to optimize the response affected by multiple factors [17-19]. In this paper, the model of a marine dual-fuel engine is built to calculate and predict the performance and emissions. The model combines the two-zone model and predict model and has the ability to calculate and predict emissions. According to references [13-16], the effects of three parameters of boost pressure, compression ratio, and intake valve closing on performance and emissions are considered. The RSM method is used to optimize the influence factors to the emissions and performance.

\section{Dual-Fuel Engine Modelling and Calibration}

2.1. Dual-Fuel Engine. In this paper, the type of the researched engine is MAN 51/60 DF dual-fuel engine. The structure and principle of dual-fuel engine are similar to the diesel engines, while fuel type is the variable and the control system is complicated. In the gas mode, diesel is used as the pilot fuel to ignite the natural gas, and the gas mode can be smoothly switched to the diesel mode. When running in the gas mode, the engine can fulfil the strict IMO Tier III $\mathrm{NO}_{X}$ limitations prescribed for Emissions Control Zones [20]. The main parameters of the engine are reported in Table 1.

2.2. Modelling and Calibration. In this paper, the AVLBOOST software [21] is used to build the model and investigate the performance and emissions of the dual-fuel engine. All measurements of this engine are from the official workshop test report certified by CCS (China Classification Society) and LR (Lloyd's Register of Shipping). The performance and emissions experimental data and the MAP of the turbocharger required for building and calibrating are acquired from the test report and the project guide [20]. The steps to build the model are as follows. Initially, the modules are selected from the model tree and arranged in a regular location. Then, the pipe is used to connect the modules. Next, the required data are needed to input into the models. For example, the general engine structural data, the intake and exhaust valve lift curve, the parameter of the heat transfer model, and the heat release model are required in the cylinder module. In order to simplify the modelling process, in the first calibration, only the intake manifold and the exhaust manifold are required to the bounder condition. In addition, a turbocharger and an intercooler are added for the second calibration. Finally, the parameters of the model are fine-tuned to obtain higher accuracy. Figure 1 displays the engine model in AVL-BOOST environment.
TABLE 1: Specification of dual-fuel engine (100\% load).

\begin{tabular}{lc}
\hline Engine parameters & Specifications \\
\hline Cylinder number $(-)$ & 8 \\
Cylinder diameter $(\mathrm{mm})$ & 510 \\
Stroke $(\mathrm{mm})$ & 600 \\
Compression ratio $(-)$ & 13.3 \\
Power $(\mathrm{kW})$ & 8000 \\
Speed $\left(\mathrm{r} \cdot \mathrm{min}^{-1}\right)$ & 514 \\
Fire order $(-)$ & $1-4-7-6-8-5-2-3$ \\
\hline
\end{tabular}

For the cylinder part, the Vibe heat release model is used to calculate the heat release rate. The Vibe heat release law is simple and practical and has a wide range of applications [21]. The model is described as follows:

$$
\left\{\begin{array}{l}
\frac{\mathrm{d} x}{\mathrm{~d} \alpha}=\frac{a}{\Delta \alpha_{c}} \cdot(m+1) \cdot y^{m} \cdot e^{-a \cdot y(m+1)}, \\
y=\frac{\alpha-\alpha_{0}}{\Delta \alpha_{c}} .
\end{array}\right.
$$

The Woschni heat transfer model is used to calculate the heat loss from the cylinder wall. The model converts complex heat transfer processes into heat transfer coefficients, which makes calculations simply and accurate [22]. The model is described as follows:

$$
\alpha_{w}=C_{0} D^{-0.2} p^{0.8} T^{-0.53} \times\left[C_{1} \cdot C_{m}+C_{2} \cdot \frac{V_{D} T_{1}}{P_{1} V_{1}}\left(p-p_{\mathrm{mot}}\right)\right]^{0.8} .
$$

The calibration results show that the shape parameters of combustion heat release are the same in the gas mode, the combustion duration and ignition delay also change, and in the fuel mode, and the shape parameters of heat release change. Due to the small proportion of pilot diesel in the gas mode (only $1 \%$ to $3 \%$ ), the Hires et al. model is used to predict the heat release [23]. The model is described as follows:

$$
\begin{aligned}
\Delta \alpha_{c} & =\Delta \alpha_{c, \text { ref }} \cdot\left(\frac{n}{n_{\text {ref }}} \cdot \frac{f_{\text {ref }}}{f}\right)^{1 / 3} \cdot\left(\frac{s_{\text {ref }}}{s}\right)^{2 / 3}, \\
\operatorname{id} & =\operatorname{id}_{\text {ref }} \cdot\left(\frac{n}{n_{\text {ref }}}\right)^{1 / 3} \cdot\left(\frac{f}{f_{\text {ref }}} \cdot \frac{s_{\text {ref }}}{s}\right)^{2 / 3} .
\end{aligned}
$$

The two-zone combustion model is used to calculate the burned zone $(b)$ and unburned zone $(u)$ temperature [24] (see equation (4)). The data of burned zone temperature is used to calculate the $\mathrm{NO}_{X}$ emissions. The extended Zeldovich mechanism is used to calculate $\mathrm{NO}_{X}$ emissions, which are calibrated for the $100 \%, 75 \%, 50 \%$, and $25 \%$ Load. The temperature distribution in the cylinder cannot be calculated by the two-zone model, and the $\mathrm{NO}_{X}$ emissions only represent the trends for different simulation [16]. However, in this study, the parameter adjustments are limited in the same load, so the two-zone model can fulfil the research. 


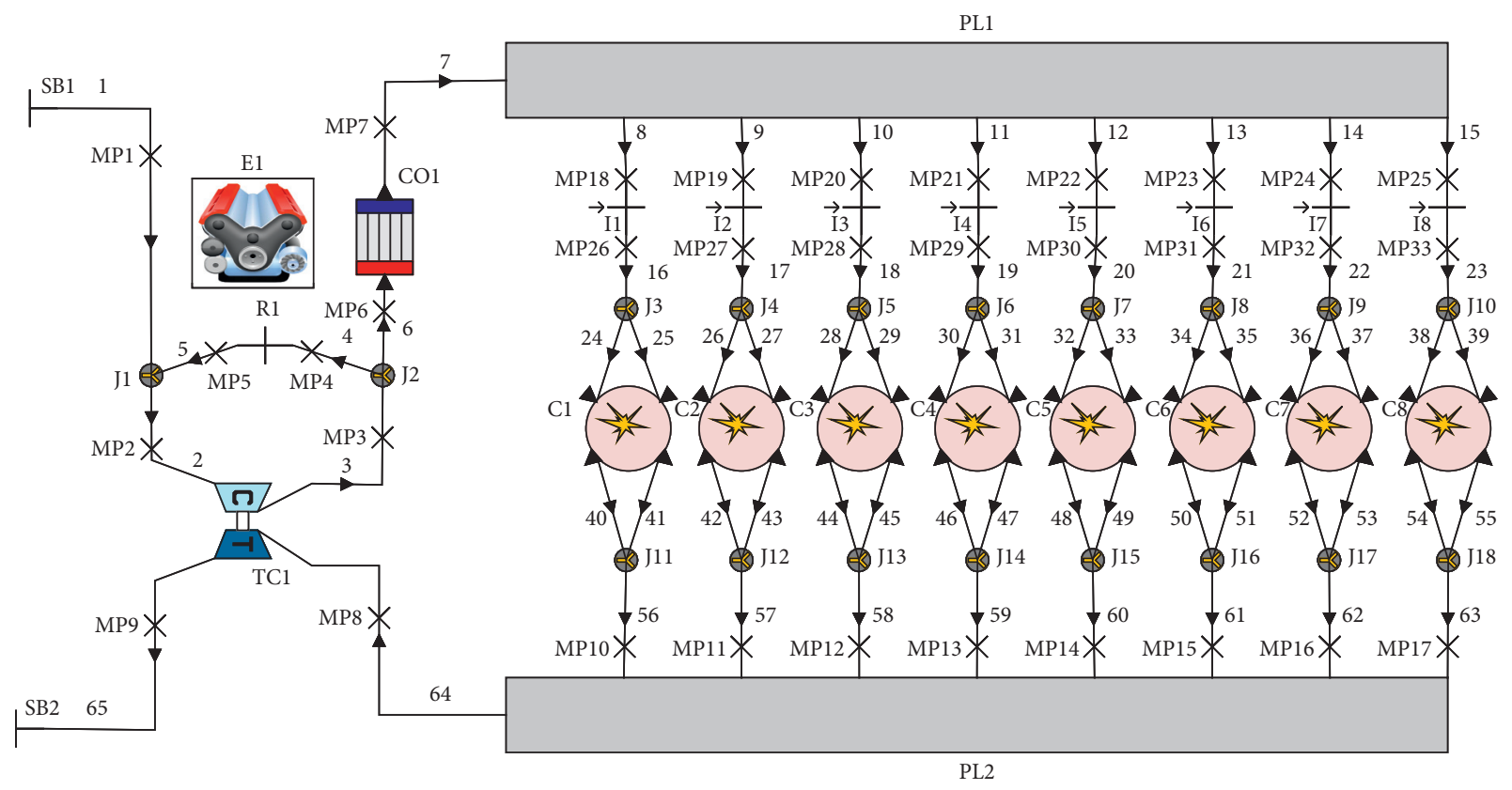

Figure 1: 8L51/60DF engine model in the AVL-BOOST environment.

$$
\left\{\begin{array}{l}
\frac{\mathrm{d} m_{b} u_{b}}{\mathrm{~d} \varphi}=-p \frac{\mathrm{d} V_{b}}{\mathrm{~d} \varphi}+\frac{\mathrm{d} Q_{F}}{\mathrm{~d} \varphi}-\sum \frac{\mathrm{d} Q_{W b}}{\mathrm{~d} \varphi}+h_{u} \frac{\mathrm{d} m_{u}}{\mathrm{~d} \varphi} \\
\frac{\mathrm{d} m_{u} u_{u}}{\mathrm{~d} \varphi}=-p \frac{\mathrm{d} V_{u}}{\mathrm{~d} \varphi}-\sum \frac{\mathrm{d} Q_{W u}}{\mathrm{~d} \varphi}+h_{u} \frac{\mathrm{d} m_{B}}{\mathrm{~d} \varphi} .
\end{array}\right.
$$

Table 2 shows the errors between calculated and measured under different loads with all of the errors less than $3 \%$. Figure 2 displays the simulated and measured cylinder pressure. According to the results of the errors, the accuracy of the simulation model can be demonstrated, which can meet the next research requirements.

\section{RSM for Optimization}

3.1. Analysis of Influencing Factors of Engine Performance and Emissions. This section focuses on the effects of engine parameters on the performance and emissions. As shown in Table 2, $\mathrm{NO}_{X}$ emissions of $50 \%$ load is higher than other loads. As a generator power engine, it is hard to work under $25 \%$ loads, so the $50 \%$ load is chosen for optimization. The engine parameters including boost pressure, compression ratio, and intake valve closing timing changed from $-10 \%$ to $+10 \%$ of base parameters. In order to get the objective results, the same intake air temperature is maintained in all simulations. Figure 3 displays the performance and emissions based on the originated operation. As it shows, the Power and BSFC are more affected by compression ratio, the $\mathrm{NO}_{X}$ emissions is more influenced by the boost pressure and intake valve closing, and the peak combustion pressure $\left(P_{\max }\right)$ is more affected by compression ratio and intake valve closing.
3.2. RSM Model. RSM is a collection of mathematical and statistical methods, which is used to modelling, prediction, and optimization. The general expression of the mathematical model is as follows [25]:

$$
y=\beta_{0}+\sum_{i=1}^{k} \beta_{i} x_{i}+\sum \sum_{i<j} \beta_{i j} x_{i} x_{j}+\sum_{i=1}^{k} \beta_{i i} x_{i}^{2}+\varepsilon,
$$

where $y$ is the response, $x_{i}$ are numeric values of the factors, terms $\beta_{0}, \beta_{i}, \beta_{i i}$, and $\beta_{i j}$ are regression coefficients, and the $\varepsilon$ is error [26]. The quadratic model is used to approximate most engine systems [18]. The difference between the predicted and actual values is called residuals. Figure 4 shows the predicted and actual values plot for Power, BSFC, $\mathrm{NO}_{X}$, and $P_{\max }$. The predicted and the actual data are approximately acceptable, and there is no large deviation between them.

The significant test is used to ensure the adaptability and accuracy of the model. The evaluation parameters are shown as follows.

$$
R^{2}=1-\left[\frac{\mathrm{SS}_{\text {residual }}}{\mathrm{SS}_{\text {residual }}+\mathrm{SS}_{\text {model }}}\right] .
$$

$R^{2}$ : a fully fitted measure that reflects how well the response surface meets the given data which is required greater than 0.9 .

$$
R_{\text {Adj. }}^{2}=1-\left[\frac{\mathrm{SS}_{\text {residual }} / d f_{\text {residual }}}{\left(\left(\mathrm{SS}_{\text {residual }}+\mathrm{SS}_{\text {model }}\right) /\left(d f_{\text {residual }}+d f_{\text {model }}\right)\right)}\right] \text {. }
$$

Adjusted- $R^{2}$ : representing the degree of correlation between all independent variables and dependent variables, the regression effect is better when close to 1 . 
TABLe 2: Calculation error of the gas mode.

\begin{tabular}{|c|c|c|c|c|}
\hline Engine load (\%) & 100 & 75 & 50 & 25 \\
\hline Mode & Gas mode error $(\%)$ & & & \\
\hline Power $(\mathrm{kW})$ & 0.12 & 0.14 & -0.09 & 0.38 \\
\hline BSFC $\left(g \cdot k^{-1} W^{-1} h^{-1}\right)$ & -0.09 & -0.11 & 0.13 & -0.34 \\
\hline Peak comb. press. (bar) & -1.81 & -1.72 & 0.44 & 0.51 \\
\hline Intake manifold temp. $(\mathrm{K})$ & -0.99 & -0.64 & 0.34 & -2.00 \\
\hline Intake manifold press. (bar) & -0.04 & -0.24 & -0.12 & -0.11 \\
\hline Intake manifold mass flow $\left(\mathrm{kg} \cdot \mathrm{s}^{-1}\right)$ & -0.12 & -0.22 & 0.16 & 0.67 \\
\hline Exhaust manifold temp. (K) & -1.98 & 0.27 & 0.10 & 2.79 \\
\hline Exhaust manifold press. (bar) & 1.28 & 2.59 & 2.23 & -0.62 \\
\hline Exhaust manifold mass flow $\left(\mathrm{kg} \mathrm{s}^{-1}\right)$ & -0.16 & 0.14 & -0.09 & 0.38 \\
\hline $\mathrm{NO}_{X}$ emissions $\left(\mathrm{g} \cdot \mathrm{k}^{-1} \mathrm{~W}^{-1} \mathrm{~h}^{-1}\right)$ & 1.59 & -2.43 & -1.96 & 1.98 \\
\hline
\end{tabular}

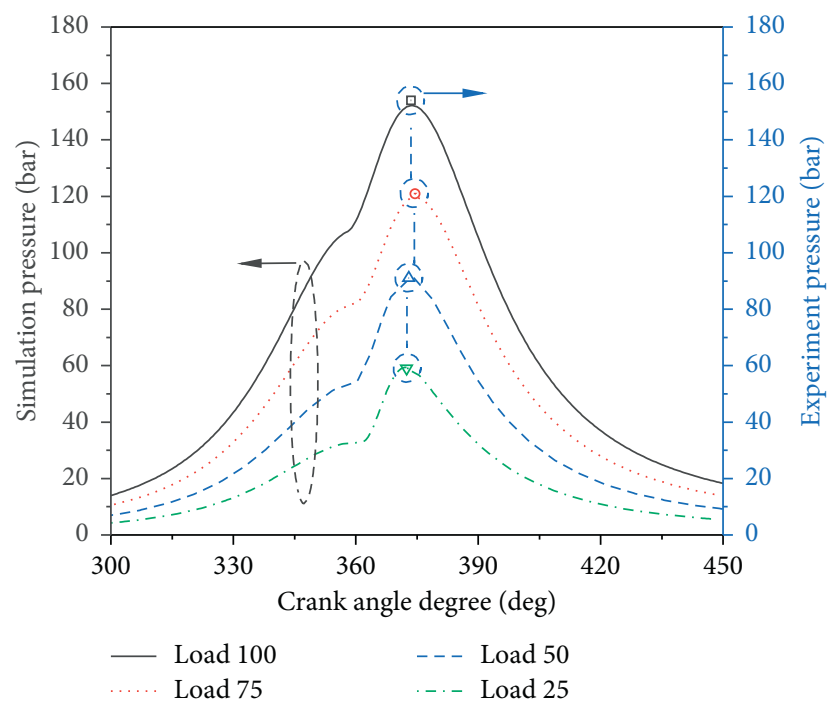

Figure 2: Comparison of simulation and experiment pressure.
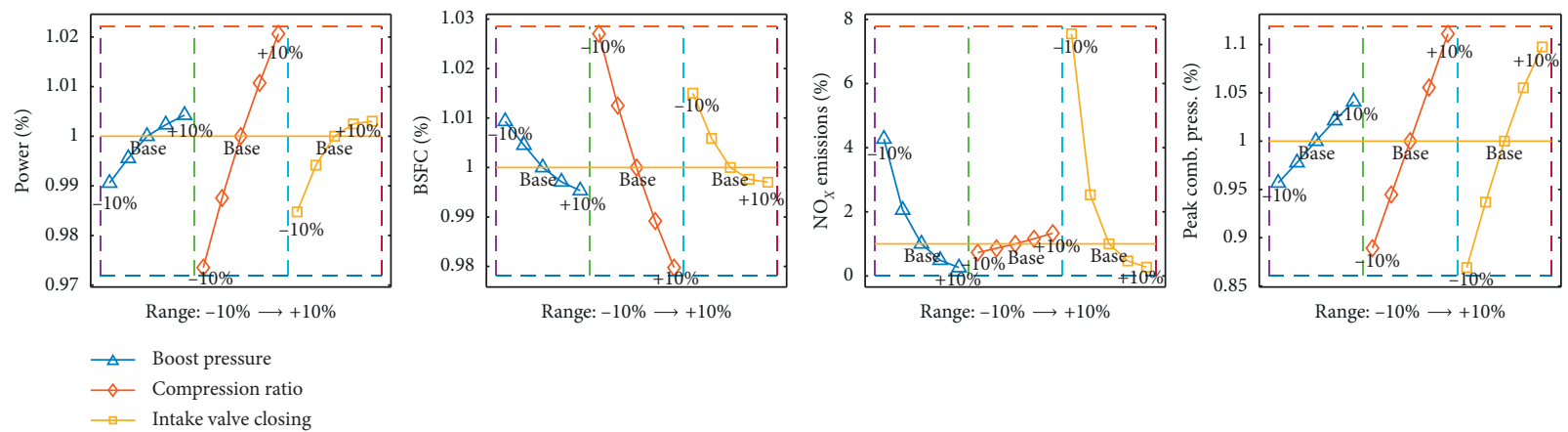

FIGURE 3: Effects of the boost pressure, compression ratio, and intake valve closing on power, $\mathrm{BSFC} \mathrm{NO}_{X}$ emissions, and peak combustion pressure.

$$
R_{\text {Pred. }}^{2}=1-\left[\frac{\text { PRESS }}{\mathrm{SS}_{\text {residual }}+\mathrm{SS}_{\text {model }}}\right] .
$$

Predicted- $R^{2}$ : a measurement of the amount of variation in new data explained by the model which is usually required greater than 0.8 , and the difference value with Adjusted $R^{2}$ should be within 0.20 . In the abovementioned equations, the SS, PRESS, and $d f$ represent the sum of squares, sum of squares of prediction errors, and degree of freedom, respectively. The ANOVA data of the Power, BSFC, $\mathrm{NO}_{X}$, and $P_{\max }$ are listed in Table 3 . It is shown that the $R^{2}$, Adjusted$\mathrm{R}^{2}$, and Predicted- $\mathrm{R}^{2}$ of all responses are greater than 0.85 , and the difference value of Adjusted $-R^{2}$ and Predicted $-R^{2}$ are less than 0.2 . It indicates the response surface models have good consistency and predictability for the test results. The $p$ value of the quadratic model is less than 0.05 , which 


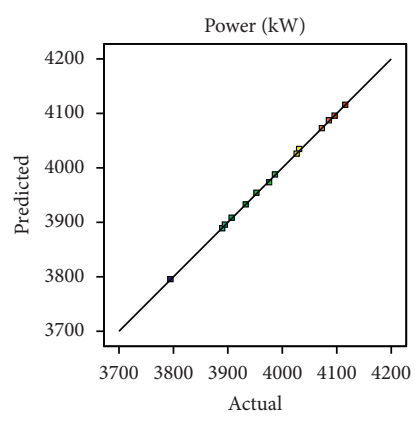

(a)

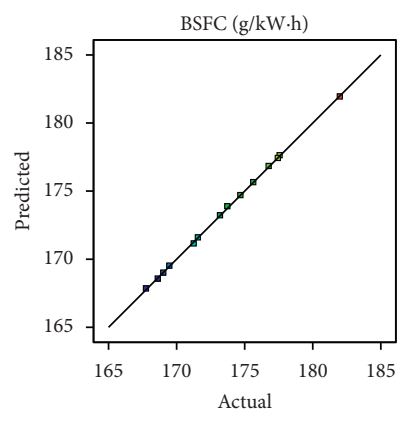

(b)

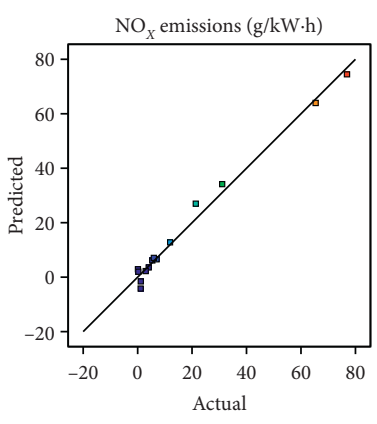

(c)

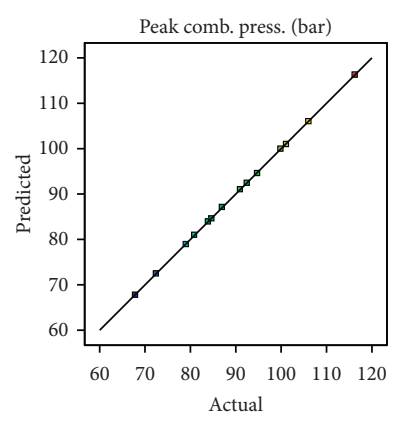

(d)

FIGURE 4: Comparison of predicted and actual parameters.

TABle 3: ANOVA table for power, BSFC, $\mathrm{NO}_{X}$, and $P_{\max }$.

\begin{tabular}{|c|c|c|c|c|c|c|c|c|}
\hline \multirow{3}{*}{$\begin{array}{l}\text { Source } \\
\text { Type }\end{array}$} & \multirow{2}{*}{\multicolumn{2}{|c|}{$\begin{array}{c}\text { Power }(\mathrm{kW}) \\
\text { Quadratic }\end{array}$}} & \multirow{2}{*}{\multicolumn{2}{|c|}{$\begin{array}{c}\text { BSFC (g/kWh) } \\
\text { Quadratic }\end{array}$}} & \multirow{2}{*}{\multicolumn{2}{|c|}{$\begin{array}{c}\mathrm{NO}_{X}(\mathrm{~g} / \mathrm{kWh}) \\
\text { Quadratic }\end{array}$}} & \multirow{2}{*}{\multicolumn{2}{|c|}{$\begin{array}{l}P_{\max } \text { (bar) } \\
\text { Quadratic }\end{array}$}} \\
\hline & & & & & & & & \\
\hline & $p$ value & $\%$ & $p$ value & $\%$ & $p$ value & $\%$ & $p$ value & $\%$ \\
\hline Model & $<0.0001$ & & $<0.0001$ & & 0.0018 & & $<0.0001$ & \\
\hline$x$ & $<0.0001$ & 19.04 & $<0.0001$ & 19.43 & 0.0006 & 43.56 & $<0.0001$ & 15.41 \\
\hline$y$ & $<0.0001$ & 58.58 & $<0.0001$ & 58.61 & 0.1995 & 6.72 & $<0.0001$ & 41.23 \\
\hline$z$ & $<0.0001$ & 22.39 & $<0.0001$ & 21.96 & 0.0003 & 49.72 & $<0.0001$ & 43.36 \\
\hline$x y$ & 0.0779 & & 0.0211 & & 0.6097 & & 0.0004 & \\
\hline$x z$ & $<0.0001$ & & 0.0001 & & 0.0012 & & 0.0002 & \\
\hline$y z$ & 0.8902 & & 0.1534 & & 0.3448 & & $<0.0001$ & \\
\hline$x^{2}$ & 0.0071 & & 0.0099 & & 0.1262 & & 0.217 & \\
\hline$y^{2}$ & 0.0034 & & 0.002 & & 0.826 & & 0.9557 & \\
\hline$z^{2}$ & 0.0002 & & 0.0002 & & 0.0261 & & 0.0001 & \\
\hline$R^{2}$ & & 0.9998 & & 0.9997 & & 0.9877 & & 1.0000 \\
\hline Adj. $-R^{2}$ & & 0.9993 & & 0.9992 & & 0.9599 & & 0.9999 \\
\hline Pred. $-R^{2}$ & & 0.9978 & & 0.9972 & & 0.8755 & & 0.9995 \\
\hline
\end{tabular}

indicates that the model terms are significant. The weight value of boost pressure $(x)$, compression ratio $(y)$, and intake valve closing $(z)$ of all response models correspond to the analysis results of Figure 3 .

\section{Results and Discussion}

4.1. Evaluation of Power. The developed quadratic model of Power as fitted based on RSM in terms of the simulated factors corresponded to

$$
\begin{aligned}
\text { Power }= & 4011.94 \\
& +30.47 \times x+93.74 \times y+35.82 \times z \\
& -2.10 x y-14.15 \times x z-0.1312 \times y z \\
& -8.18 x^{2}-10.01 \times y^{2}-21.90 \times z^{2}
\end{aligned}
$$

where Power is the engine output power $(\mathrm{kW}), x$ is the boost pressure (bar), $y$ is the compression ratio (-), and the $z$ is the intake valve closing $(\operatorname{degC})$. The predicted values of Power calculated by equation (9) are satisfactorily close to the simulation values.

The effects of linear factors boost pressure, compression ratio, and intake valve closing are found to be highly significant (all $p$ value $<0.0001$ ) on the Power. All of the square terms are also found to be significant with $p$ value: $x^{2}(0.0071)$, $y^{2}(0.0034)$, and $z^{2}(0.0002)$ which means there is a curved line relationship between the variables and Power. $x$ and $z$ are also found to have an interaction effect on Power with the $p$ value: $x z(<0.0001)$. A negative sign means an antagonistic effect, while a positive sign of the coefficient represents a synergistic effect. The regression statistics goodness of fit $\left(R^{2}\right)$, the goodness of adjustment (Adjusted- $R^{2}$ ), and the goodness of prediction (Predicted- $R^{2}$ ) for the response of Power are $99.98 \%, 99.93 \%$, and $99.78 \%$, respectively. All of the three values indicate that the model fits the data very well.

The effect of boost pressure, compression ratio, and intake valve closing on the Power is depicted in Figure 5. The higher boost pressure and compression ratio and the later intake valve closing could improve the Power [16]. Among the abovementioned factors, compression ratio has the greatest influence on the Power. This is because higher compression ratios make the higher temperatures and pressures in the cylinder at the end of compression and increase the charge energy in the cylinder [27].

4.2. Evaluation of BSFC. The developed quadratic model of BSFC as fitted based on RSM in terms of the simulated factors corresponded to 


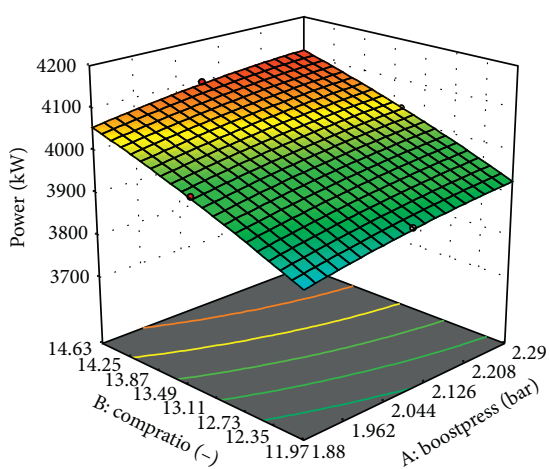

(a)

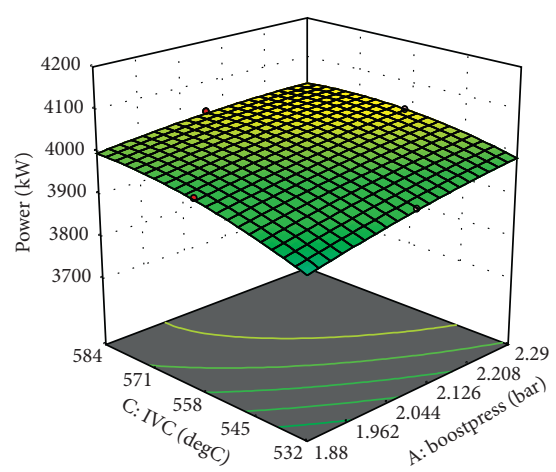

(b)

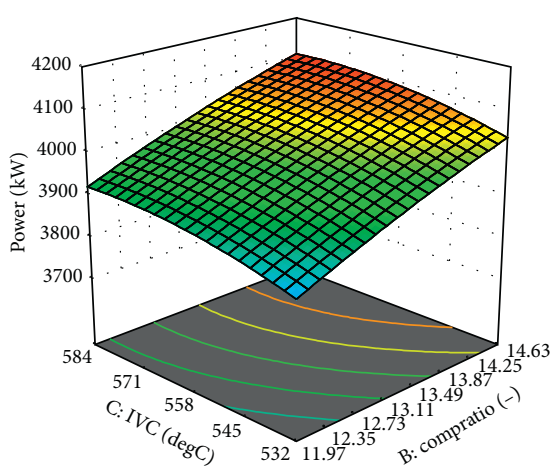

(c)

FIGURE 5: Surface plot of power with input variables.

$$
\begin{aligned}
\mathrm{BSFC}= & 172.16 \\
& -1.37 \times x-4.13 \times y-1.55 \times z \\
& +0.1548 x y+0.6334 \times x z+0.0739 \times y z \\
& +0.3494 x^{2}+0.5402 \times y^{2}+0.9777 \times z^{2}
\end{aligned}
$$

where BSFC is the brake-specific fuel consumption $(\mathrm{g} / \mathrm{kWh})$, $x$ is the boost pressure (bar), $y$ is the compression ratio (-), and $z$ is the intake valve closing $(\operatorname{degC})$. The predicted values of BSFC calculated by (10) are satisfactorily close to the simulation values.

The effects of linear factors boost pressure, compression ratio, and intake valve closing are found to be highly significant (all $p$ value $<0.0001$ ) on the BSFC. All of the square terms are also found to be significant with $p$ value: $x^{2}$ (0.0099), $y^{2}(0.0020)$, and $z^{2}(0.0002)$ which means there is a curved-line relationship between the variables and BSFC. The $x y$ and $x z$ are also found to have an interaction effect on BSFC with the $p$ value: $x y(0.0211)$ and $x z$ (0.0001). A negative sign means an antagonistic effect, while a positive sign of the coefficient represents a synergistic effect. The regression statistics goodness of fit $\left(R^{2}\right)$, the goodness of adjustment (Adjusted- $R^{2}$ ), and the goodness of prediction (Predicted- $R^{2}$ ) for the response of BSFC are $99.97 \%, 99.92 \%$, and $99.72 \%$, respectively. All of the three values indicate that the model fits the data very well. The effect of boost pressure, compression ratio, and intake valve closing on the BSFC is depicted in Figure 6. Similar to the Power, the compression ratio has the greatest influence on BSFC [28].

4.3. Evaluation of $\mathrm{NO}_{X}$. The developed quadratic model of $\mathrm{NO}_{X}$ emissions as fitted based on RSM in terms of the simulated factors corresponded to

$$
\begin{aligned}
\mathrm{NO}_{X}= & 5.23 \\
& +5.23 \times x-15.59 \times y+2.41 \times z \\
& -17.80 x y-0.9689 \times x z+14.29 \times y z \\
& -1.87 x^{2}-0.7412 \times y^{2}+10.89 \times z^{2}
\end{aligned}
$$

where $\mathrm{NO}_{X}$ is the engine $\mathrm{NO}_{X}$ emissions ( $\left.\mathrm{g} / \mathrm{kWh}\right), x$ is the boost pressure (bar), $y$ is the compression ratio (-), and the $z$ is the intake valve closing ( $\operatorname{degC})$. The predicted values of $\mathrm{NO}_{X}$ calculated by (11) are satisfactorily close to the simulation values. The effects of linear factors boost pressure and intake valve closing are found to be highly significant ( $p$ value $=0.0006$ and 0.0003 ) on the $\mathrm{NO}_{X}$. The $z$ square terms are also found to be significant with $p$ value: $z^{2}(0.0261)$, which means there is a curved line relationship between the variables and $\mathrm{NO}_{X} . x$ and $z$ are also found to have an interaction effect on $\mathrm{NO}_{X}$ with the $p$ value: $x z$ (0.0012). A negative sign means an antagonistic effect, while a positive sign of the coefficient represents a synergistic effect. The regression statistics goodness of fit $\left(R^{2}\right)$, the goodness of adjustment (Adjusted- $R^{2}$ ), and the goodness of prediction (Predicted- $R^{2}$ ) for the response of $\mathrm{NO}_{X}$ are $98.77 \%, 95.99 \%$, and $87.55 \%$, respectively. Compared with other response, the regression effect of $\mathrm{NO}_{X}$ is not good, which is also related to the limitation of the two-zone model [29]. The effect of boost pressure, compression ratio, and intake valve closing on the $\mathrm{NO}_{X}$ are depicted in Figure 7.

4.4. Evaluation of $P_{\max }$. The developed quadratic model of $P_{\text {max }}$, as fitted based on RSM in terms of the simulated factors corresponded to

$$
\begin{aligned}
P_{\max }= & 91.01 \\
& +3.74 \times x+10.00 \times y+10.52 \times z \\
& +0.6096 x y+0.7907 \times x z+1.32 \times y z \\
& -0.1503 x^{2}-0.0061 \times y^{2}-1.54 \times z^{2},
\end{aligned}
$$

where $P_{\max }$ is the engine peak combustion pressure (bar), $x$ is the boost pressure (bar), $y$ is the compression ratio (-), and the $z$ is the intake valve closing ( $\operatorname{degC})$. The predicted values of Power calculated by (12) are satisfactorily close to the simulation values.

The effects of linear factors boost pressure and compression ratio and intake valve closing are found to be highly significant (all $p$ value $<0.0001$ ) on the $P_{\max }$. The $z$ square terms are also found to be significant with $p$ value: $z^{2}$ (0.0001), which means there is a curved line relationship between the variables and $P_{\max }$. The terms $x y, x z$, and $y z$ are also found to have an interaction effect on $P_{\max }$ with the $p$ 


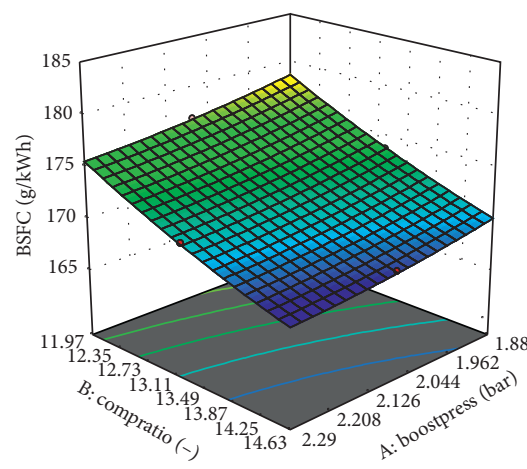

(a)

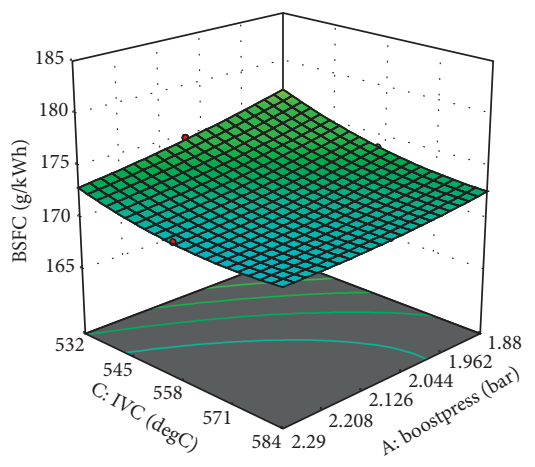

(b)

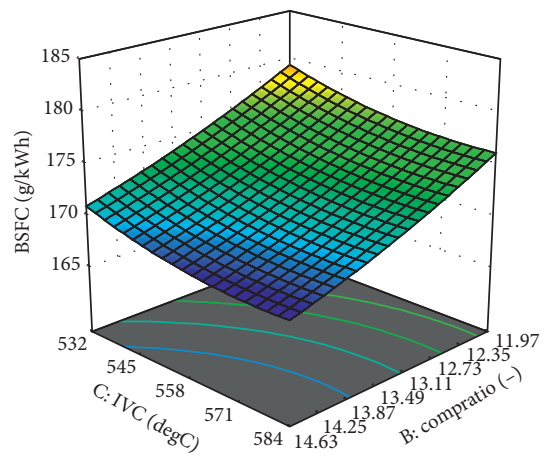

(c)

FIgURE 6: Surface plot of BSFC with input variables.

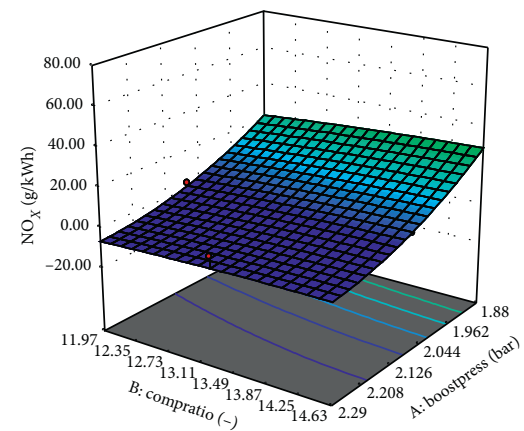

(a)

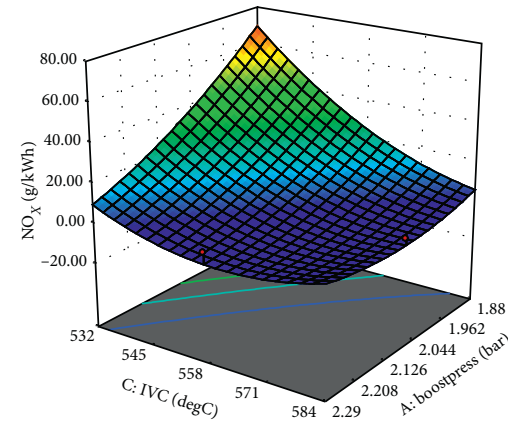

(b)

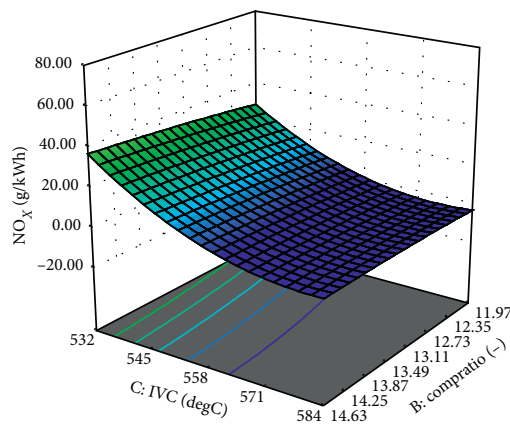

(c)

FIgURE 7: Surface plot of $\mathrm{NO}_{X}$ with input variables.

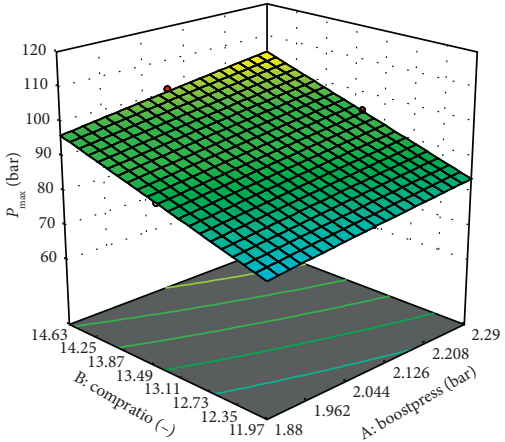

(a)

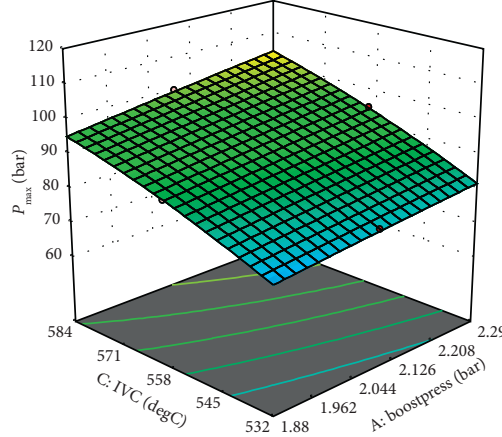

(b)

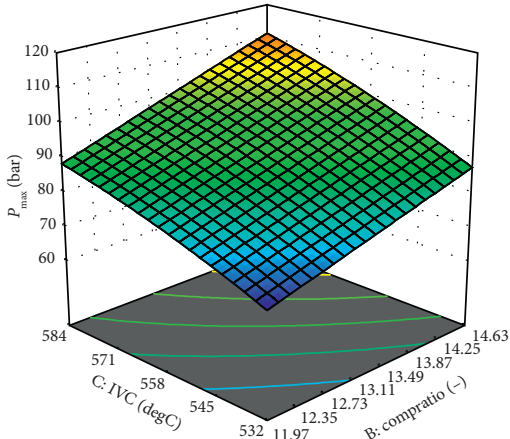

(c)

Figure 8: Surface plot of $P_{\max }$ with input variables.

value: $x y$ (0.0004), $x z(0.0002)$, and $y z(<0.0001)$. A negative sign means an antagonistic effect, while a positive sign of the coefficient represents a synergistic effect. The regression statistics goodness of fit $\left(R^{2}\right)$, the goodness of adjustment (Adjusted- $R^{2}$ ), and the goodness of prediction (Predicted$R^{2}$ ) for the response of $P_{\max }$ are $1.0000 \%, 99.99 \%$, and $99.95 \%$, respectively. All of the three values indicate that the model fits the data very well.

The effect of boost pressure, compression ratio, and intake valve closing on the $P_{\max }$ is depicted in Figure 8. The higher boost pressure and compression ratio and the later intake valve closing could improve the $P_{\max }$. Among the abovementioned factors, compression ratio and intake valve closing both have the greatest influence on the $P_{\max }$.

4.5. Comparison between RSM and Simulation Results. In order to obtain the best parameter setting of low emissions without sacrificing performance, the responses Power is limited to not less than the original level. The BSFC, $\mathrm{NO}_{X}$, and $P_{\max }$ are limited to not more than the original level. The best parameter settings boost pressure (+9.83\%), 
TABLE 4: Comparison between RSM and simulation results.

\begin{tabular}{lcccc}
\hline Terms & $\triangle$ power $(\mathrm{kW})$ & $\begin{array}{c}\triangle \mathrm{BSFC} \\
(\mathrm{g} / \mathrm{kWh})\end{array}$ & $\begin{array}{c}\triangle \mathrm{NO}_{X} \\
(\mathrm{~g} / \mathrm{kWh})\end{array}$ & $\triangle P_{\max }($ bar $)$ \\
\hline RSM & $+0.54 \%$ & $-0.59 \%$ & $-17.18 \%$ & $-1.55 \%$ \\
Simulation & $+0.55 \%$ & $-0.60 \%$ & $-13.21 \%$ & $-1.51 \%$ \\
\hline
\end{tabular}

compression ratio $(+2.42 \%)$, and intake valve closing $(-6.04 \%)$, leading to the Power, $\mathrm{BSFC}, \mathrm{NO}_{X}$, and $P_{\max }$ change separately $0.54 \%,-0.59 \%,-17.18 \%$, and $-1.55 \%$ with the RSM method. Due to the early timing of intake valve closing and the charge of cylinder expansion and cooling, the in-cylinder temperature is lower than the original cycle. The early intake valve closing timing needs the higher boost pressure, so that there is enough air for combustion. The higher boost pressure causes more air to enter the cylinder, which makes the fuel burn more thoroughly. The higher compression ratio causes higher in-cylinder temperature during the compression phase which makes the combustion temperature high. It has an opposite effect when the intake valve closing advanced, so the optimized result shows that the compression ratio increases less. Table 4 displays the same parameter settings on the simulation results. The Power, BSFC, and $P_{\max }$ simulated values are in good agreement with the predicted values. Because the two-zone model cannot well calculate the temperature distribution in the cylinder, the calculated RSM value is different from the simulated value when calculating $\mathrm{NO}_{X}$ emissions [30]. Although the model has deviations, it does not affect the trend judgment of the influence of different parameters on $\mathrm{NO}_{X}$. RSM optimization results are still convincing, which can optimize different parameters at the same time. The RSM method transforms time-consuming model calculation into mathematical calculation, which has certain advantages in speed and accuracy. The model based on the RSM method can predict with adequate accuracy the engine performance and emissions for the gas mode operation, which can be used in the engine design process for optimizing the engine settings.

\section{Conclusion}

This study investigated the effects of boost pressure, compression ratio, and intake valve closing on the performance and emissions characteristics of the marine dual-fuel engine. The research is conducted by using a full-factorial experimental design matrix. The response surface method is used to model, predict, and optimize the measured response variables. The conclusions of the analysis are as follows:

(1) The results of ANOVA indicated that all the models for Power, BSFC, $\mathrm{NO}_{X}$, and $P_{\max }$ are found to be significant under $99 \%$ confidence level. For the power and BSFC, the compression ratio is the major influence (about 58.58\% and 58.61\%). For the $\mathrm{NO}_{X}$, the boost pressure and intake valve closing are the major influence (about $43.56 \%$ and $49.72 \%$ ). For the $P_{\max }$, the compression ratio and intake valve closing are the major influence (about $41.23 \%$ and $43.36 \%$ ).
The results of ANOVA are consistent with the single change parameter analysis result.

(2) From the response surface plots, it can be concluded that the effects of all factors on the responses are very straightforward, and it is easy to find a single response optimal value and limit the range of different responses and perform multiobjective optimization.

(3) The optimization results are very close to simulation results which indicate the accuracy of the RSM model from another perspective. The Power, BSFC, $\mathrm{NO}_{X}$, and $P_{\max }$ change by $0.55 \%,-0.60 \%,-13.21 \%$, and $-1.5 \%$ separately when the parametric settings with boost pressure, compression ratio, and intake valve closing change by $+9.83 \%,+2.42 \%$, and $-6.04 \%$, separately.

\section{Data Availability}

The data used to support the findings of this study are available from the corresponding author upon request.

\section{Conflicts of Interest}

The authors declare that there are no conflicts of interest regarding the publication of this paper.

\section{Acknowledgments}

The research work has been financially supported by the People's Republic of China Project "Intelligent Ship Comprehensive Testing and Verification Research" ((2018) no. 473 ) and "the Fundamental Research Funds for the Central Universities” (no. 3132019315).

\section{References}

[1] N. Späth, "DNV GL releases updated DNV GL NO ${ }_{x}$ TIER III compliance guide," 2017, https://www.dnvgl.com/news/dnv-glreleases-updated-dnv-gl-nox-tier-iii-compliance-guide-98168.

[2] B. Rajesh kumar and S. Saravanan, "Effect of exhaust gas recirculation (EGR) on performance and emissions of a constant speed DI diesel engine fueled with pentanol/diesel blends," Fuel, vol. 160, pp. 217-226, 2015.

[3] A. P. Carlucci, D. Laforgia, R. Saracino, and G. Toto, "Combustion and emissions control in diesel-methane dualfuel engines: the effects of methane supply method combined with variable in-cylinder charge bulk motion," Energy Conversion and Management, vol. 52, no. 8-9, pp. 3004-3017, 2011.

[4] C. D. Rakopoulos, K. A. Antonopoulos, D. C. Rakopoulos, and D. T. Hountalas, "Multi-zone modeling of combustion and emissions formation in DI diesel engine operating on ethanol-diesel fuel blends," Energy Conversion and Management, vol. 49, no. 4, pp. 625-643, 2008.

[5] G. Gonca, "Investigation of the effects of steam injection on performance and NO emissions of a diesel engine running with ethanol-diesel blend," Energy Conversion and Management, vol. 77, pp. 450-457, 2014.

[6] X. Ma, F. Zhang, K. Han, Z. Zhu, and Y. Liu, "Effects of intake manifold water injection on combustion and emissions of 
diesel engine," Energy Procedia, vol. 61, no. 1, pp. 777-781, 2014.

[7] G. Gonca and B. Sahin, "Effect of turbo charging and steam injection methods on the performance of a Miller cycle diesel engine (MCDE)," Applied Thermal Engineering, vol. 118, no. 1, pp. 138-146, 2017.

[8] Z. Chen, L. Wang, Q. Zhang, X. Zhang, B. Yang, and K. Zeng, "Effects of spark timing and methanol addition on combustion characteristics and emissions of dual-fuel engine fuelled with natural gas and methanol under lean-burn condition," Energy Conversion and Management, vol. 181, pp. 519-527, 2019.

[9] A. Hegab, A. La Rocca, and P. Shayler, “Towards keeping diesel fuel supply and demand in balance: dual-fuelling of diesel engines with natural gas," Renewable and Sustainable Energy Reviews, vol. 70, no. 1, pp. 666-697, 2017.

[10] M. C. Cameretti, R. Tuccillo, L. D. Simio, S. Iannaccone, and U. Ciaravola, "A numerical and experimental study of dualfuel diesel engine for different injection timings," Applied Thermal Engineering, vol. 101, pp. 630-638, 2016.

[11] G. Gonca, B. Sahin, A. Parlak et al., "The effects of steam injection on the performance and emission parameters of a Miller cycle diesel engine," Energy, vol. 78, no. 1, pp. 266-275, 2014.

[12] A.-H. Kakaee, A. Nasiri-Toosi, B. Partovi, and A. Paykani, "Effects of piston bowl geometry on combustion and emissions characteristics of a natural gas/diesel RCCI engine," Applied Thermal Engineering, vol. 102, pp. 1462-1472, 2016.

[13] S. Zhou, R. Gao, Y. Feng, and Y. Zhu, "Evaluation of Miller cycle and fuel injection direction strategies for low $\mathrm{NO}_{x}$ emission in marine two-stroke engine," International Journal of Hydrogen Energy, vol. 42, no. 31, pp. 20351-20360, 2017.

[14] X. Sun, X. Liang, G. Shu, J. Lin, Y. Wang, and Y. Wang, "Numerical investigation of two-stroke marine diesel engine emissions using exhaust gas recirculation at different injection time," Ocean Engineering, vol. 144, pp. 90-97, 2017.

[15] C. Mavrelos and G. Theotokatos, "Numerical investigation of a premixed combustion large marine two-stroke dual-fuel engine for optimising engine settings via parametric runs," Energy Conversion and Management, vol. 160, pp. 48-59, 2018.

[16] S. Stoumpos, G. Theotokatos, E. Boulougouris, D. Vassalos, I. Lazakis, and G. Livanos, "Marine dual-fuel engine modelling and parametric investigation of engine settings effect on performance-emissions trade-offs," Ocean Engineering, vol. 157, pp. 376-386, 2018.

[17] S. Saravanan, B. Rajesh Kumar, A. Varadharajan, D. Rana, B. Sethuramasamyraja, and G. Lakshmi Narayana rao, "Optimization of DI diesel engine parameters fueled with isobutanol/diesel blends-response surface methodology approach," Fuel, vol. 203, pp. 658-670, 2017.

[18] S. Kumar and P. Dinesha, "Optimization of engine parameters in a bio diesel engine run with honge methyl ester using response surface methodology," Measurement, vol. 125, pp. 224-231, 2018.

[19] G. Khoobbakht, G. Najafi, M. Karimi, and A. Akram, "Optimization of operating factors and blended levels of diesel, biodiesel and ethanol fuels to minimize exhaust emissions of diesel engine using response surface methodology," Applied Thermal Engineering, vol. 99, pp. 1006-1017, 2016.

[20] M. D. Turbo, 51/60DF Project Guide-Marine: Four-Stroke Dual-Fuel Engines Compliant with IMO Tier II/IMO Tier III, MAN Diesel \& Turbo, Augsburg, Germany, 2015.

[21] A. List, AVL BOOST Users' Guides, AVL List GmbH, Graz, Austria, 2016.
[22] G. Woschni, "A universally applicable equation for the instantaneous heat transfer coefficient in the internal combustion engine," SAE Transactions, vol. 76, pp. 3065-3083, 1968.

[23] S. D. Hires, R. J. Tabaczynski, and J. M. Novak, "The prediction of ignition delay and combustion intervals for a homogeneous charge, spark ignition engine," SAE Transactions, vol. 87, pp. 1053-1067, 1978.

[24] G. P. Merker, B. Hohlbaum, and M. Rauscher, "Two-zone model for calculation of nitrogen-oxide formation in directinjection diesel engines," SAE Transactions, vol. 102, no. 1, pp. 2043-2050, 1993.

[25] A. I. Khuri and S. Mukhopadhyay, "Response surface methodology," Wiley Interdisciplinary Reviews: Computational Statistics, vol. 2, no. 2, pp. 128-149, 2010.

[26] B. Rajesh Kumar, S. Saravanan, D. Rana, and A. Nagendran, "Combined effect of injection timing and exhaust gas recirculation (EGR) on performance and emissions of a DI diesel engine fuelled with next-generation advanced biofuel-diesel blends using response surface methodology," Energy Conversion and Management, vol. 123, pp. 470-486, 2016.

[27] R. Kamaraj, J. Gowthami Thankachi Raghuvaran, A. Panimayam, and H. Allasi, "Performance and exhaust emission optimization of a dual-fuel engine by response surface methodology," Energies, vol. 11, no. 12, p. 3508, 2018.

[28] S. K. Addepalli and J. M. Mallikarjuna, "Parametric analysis of a 4-stroke GDI engine using CFD," Alexandria Engineering Journal, vol. 57, no. 1, pp. 23-34, 2018.

[29] S. A. Provataris, N. S. Savva, T. D. Chountalas, and D. T. Hountalas, "Prediction of $\mathrm{NO}_{x}$ emissions for high speed DI Diesel engines using a semi-empirical, two-zone model," Energy Conversion and Management, vol. 153, pp. 659-670, 2017.

[30] C. D. Rakopoulos, D. C. Rakopoulos, G. C. Mavropoulos, and G. M. Kosmadakis, "Investigating the EGR rate and temperature impact on diesel engine combustion and emissions under various injection timings and loads by comprehensive two-zone modeling," Energy, vol. 157, pp. 990-1014, 2018. 